\title{
Changes in Polyphenolic Content and Antioxidant Activity of Grapes cv Vranac During Ripening
}

\author{
M. Andjelkovic ${ }^{1}$, B. Radovanović2, A. Radovanović2, A.M. Andjelkovic ${ }^{2 *}$ \\ (1) CBRN Training Centre, Balkanska 57, Krusevac, Serbia \\ (2) Department of Chemistry, Faculty for Mathematics and Science in Nis, Visegradska 33, Nis, Serbia
}

Submitted for publication: February 2012

Accepted for publication: April 2013

Key words: Grape ripening, total phenolics, tartaric esters, flavonols, anthocyanins, antioxidant activity

\begin{abstract}
This study characterised and evaluated the phenolic composition and antioxidant activity of the red wine grape Vranac (Vitis vinifera $L_{\text {.) }}$ from the southern Serbian vineyard region during grape ripening. Polyphenol composition at different harvest dates was determined by HPLC-DAD analysis. Antioxidant activity was estimated by DPPH assay. The study demonstrates that the Vranac variety represents important sources of dietary antioxidants. The results show that (+)-catechin, (-)-epicatechin and procyanidin dimer B2 were the most prevalent in the seeds, and quercetin and malvidin glucosides in the grape skins. All grape extracts were shown to have high radical-scavenging activity. Strong correlations between radical-scavenging activity and polyphenols suggest that the phenolic composition of the Vranac variety contributes significantly to the antioxidant capacities of grape extracts. During grape ripening there were significant changes in physiological properties and phenolic content, and it is important to determine optimal harvest time, which will ensure grapes with very good quality parameters (in our study at the 30th day after véraison).
\end{abstract}

\section{INTRODUCTION}

Grapes (Vitis vinifera L.) are important sources of antioxidants such as phenolic compounds. The antioxidant activity of dietary polyphenols is considered to be much greater than that of the essential vitamins, therefore contributing significantly to the health benefits of grapes (Banini et al., 2006; Anastasiadi et al., 2010). Over the past few years there has been increasing interest in determining the relevant dietary sources of antioxidant phenolics.

Phenolic compounds are divided into two groups: flavonoid (anthocyanins, flavan-3-ols, condensed tannins and flavonols) and non-flavonoid compounds (phenolic acids and stilbenes). The composition of each family of polyphenols is directly responsible for the special characteristics of specific grape varieties and of the resulting wine.

It is known that, while the skin of the grape berry contains condensed tannins and pigments, the seeds contain tannins and the pulp contains small quantities of those compounds and generally no pigments (Mori et al., 2005; Tsanova-Savova et al., 2005; Kennedy et al., 2006; Adams, 2006; Rodrígez et al., 2006). Condensed tannins, which are polymers of flavan-3-ol analogues, are the most abundant category of soluble polyphenols in grape berries, found predominantly in the hypodermal layers of the skin and in the soft parenchyma of the seeds (Yinrong \& Yeap Foo, 1999).
Anthocyanins are the second most important group of phenolic compounds and are also located in the thick-walled hypodermal cells of the skin. The main anthocyanin found in the skin of Vitis vinifera L. grapes is malvidin-3-glucoside, with amounts varying according to variety, ecological conditions and viticultural practices (Adams, 2006; Downey et al., 2006; Kennedy et al., 2006).

Flavonols, as the third main group of phenolic compounds (kaempferol, quercetin, myricetin, luteolin), are abundant in wine, while in grapes they are present in the form of glucosides, galactosides, glucuronides and quercetin-3rutinoside (rutin). In most cases, flavonols are less abundant than the other phenolic compounds discussed above (Revilla \& Ryan, 2000; Kennedy et al., 2006).

The importance of phenolic compounds as a healthprotecting factor has been demonstrated many times (Geenspan et al., 2005; Lee et al., 2005; Banini et al., 2006; Del Pozo-Insfran et al., 2007). For that reason, the composition of phenolic compounds in different grapes and wine, and their extractability and antioxidant properties, have often been investigated (Lacopini et al., 2008; Radovanović et al., 2010).

The aim of this work was to determine the influence of ripening stage on the phenolic composition of Vranac grapes, an important variety in southern European viticulture and winemaking. This work also sought to quantify the

*Corresponding author:E-mail: ana.andjelk@gmail.com

Aknowledgements: This research was supported by the European Union, FP7-REGPOT-2007-3-01, KBBE: Food, Agriculture, and Biotechnology, Project CHROMLAB-ANTIOXIDANT, No. 204756, and by Ministry of Science of Serbia, project numbers 031020 and 034012 
individual phenolic compounds at commercial harvest, as well as the free radical scavenging activity of Vranac grape phenolics at different stages of ripening.

\section{MATERIALS AND METHODS \\ Reagents and chemicals}

Methanol, acetonitrile, formic acid and acetic acid of HPLC grade were obtained from Merck (Darmstadt, Germany). Gallic acid, caffeic acid, t-coutaric acid, p-coumaric acid, malvidin-3-monoglucoside chloride, cyanidin-3-glucoside chloride, (+)-catechin, procyanidin B2, (-)-epicatechin, (-)-epicatechin gallate, quercetin, rutin, quercetin-glucoside, luteolin-glucoside, myricetin-glucoside, kaempferolglucoside and 2,2'-diphenyl-1-picrylhydrazyl (DPPH) free radical were supplied by Sigma Chemical Co. (St. Louis, $\mathrm{MO})$. The reagents used were of analytical quality.

\section{Sample collection}

The grape variety Vranac (Vitis vinifera L.) was collected from the southern Serbian vineyard region. Vranac ripens in mid-October, when the skin is dark blue in colour. The grapes were harvested in the 2009 harvest season. Some data for weather conditions in the southern Serbia region in 2009 are given in Table 1. This data can be used as representative, average data for this region (weather conditions have not changed significantly in the last ten years).

For analysis, 100 berries were collected every at random from each bunch 10 days after véraison (starting in the last week of August and ending in the middle of October), weighed and then crushed by hand to extract the juice. The juice was used to determine the total soluble solids $\left({ }^{\circ}\right.$ Brix $)$ using a hand-held refractometer, the titratable acidity (by titration with $\mathrm{NaOH}$ ), the $\mathrm{pH}$ (using a calibrated $\mathrm{pH}$-meter) and the maturity index defined as the ratio of total soluble solids to titratable acidity. ${ }^{\circ}$ Brix is directly related to the potential alcohol (vol\%) and the sugar content $(\mathrm{g} / \mathrm{L})$. Grapes for phenolic analysis were frozen after sampling and stored at $-20^{\circ} \mathrm{C}$. Before extraction, the seeds, skins and pulp were manually separated from the whole berries. Seeds and skins were dried at $60^{\circ} \mathrm{C}$ and measured until constant weight. Dried grape seeds and skins were crushed in a grinder for 2 min and then used for extractions.

\section{Extraction procedures}

The samples of berry seeds (0.5 g dry seeds), skins (0.5 g dry skin) and pulp ( $1 \mathrm{~g}$ fresh pulp) were extracted with $40 \mathrm{~mL}$ solvent system of methanol/acetone/water/ acetic acid (30/42/27.5/0.5) by stirring continuously at room temperature in the dark for $30 \mathrm{~min}$ and then centrifuged for $10 \mathrm{~min}$ at $2500 \mathrm{x} \mathrm{g}$. The supernatants were collected and the precipitates were extracted again with the same solvent $(40 \mathrm{~mL})$. The extracts were centrifuged $(10 \mathrm{~min}$ at $2500 \mathrm{x} \mathrm{g})$ and the supernatants were removed and combined with the previously collected supernatants to make up a final volume of the extracts. Extracts were filtered through a $0.45 \mu \mathrm{m}$ syringe filter before analysis.

\section{Total phenols}

Total phenolics in the selected extract samples were determined according to Mazza's method (Mazza et al., 1999), with some modifications as described in previous work (Radovanović \& Radovanović, 2010). Briefly, $0.25 \mathrm{~mL}$ of the diluted sample was mixed with $0.25 \mathrm{~mL}$ of $0.1 \% \mathrm{HCl}$ in $95 \%$ ethanol and $4.55 \mathrm{~mL}$ of $2 \% \mathrm{HCl}$, approximately 15 min before reading the absorbance at $280 \mathrm{~nm}$ with a UV/ VIS spectrophotometer (Agilent 8453 spectrophotometer). The absorbance at $280 \mathrm{~nm}, A_{280 \mathrm{~nm}}$, was used to estimate total phenolics (gallic acid was used as standard).

\section{Total anthocyanins}

The anthocyanins were determined according to Rigo's method (Rigo et al., 2000). Briefly, the grape skin extracts were appropriately diluted with ethanol/water/hydrochloric acid $(70 / 29 / 1)$ and the absorbance was measured at the wavelength of $540 \mathrm{~nm}$ after $15 \mathrm{~min}$. Malvidin-3-O-glucoside was employed as a calibration standard and the results were expressed as malvidin-3-O-glucoside equivalents - ME.

TABLE 1

Weather conditions in southern Serbia (2009).

\begin{tabular}{|c|c|c|c|c|c|}
\hline Year & Month & Average $\left({ }^{\circ} \mathrm{C}\right)$ & Maximum $\left({ }^{\circ} \mathrm{C}\right)$ & Minimum $\left({ }^{\circ} \mathrm{C}\right)$ & Rainy days \\
\hline \multirow{2}{*}{2008} & November & 8 & 20 & -1 & 10 \\
\hline & December & 4 & 13 & -7 & 23 \\
\hline \multirow{10}{*}{2009} & January & 0 & 14 & -10 & 19 \\
\hline & February & 2 & 11 & -3 & 22 \\
\hline & March & 6 & 18 & 1 & 24 \\
\hline & April & 13 & 16 & 10 & 12 \\
\hline & May & 17 & 23 & 10 & 15 \\
\hline & June & 20 & 25 & 15 & 10 \\
\hline & July & 22 & 26 & 16 & 11 \\
\hline & August & 22 & 27 & 18 & 8 \\
\hline & September & 18 & 25 & 13 & 21 \\
\hline & October & 12 & 18 & 4 & 22 \\
\hline \multicolumn{2}{|c|}{ Nov. 2008 - Oct. 2009} & 12 & 27 & -10 & 197 \\
\hline \multicolumn{2}{|c|}{ Aug. 2009 - Oct. 2009} & 20 & 27 & 12 & 51 \\
\hline
\end{tabular}




\section{HPLC analysis}

The polyphenol composition of the grape seeds and skin was analysed by high performance liquid chromatography (HPLC) of the extracts, previously filtered through a $0.45 \mu \mathrm{m}$-pore size membrane filter. The apparatus used for the separation and determination of individual polyphenols from the grape extracts was an Agilent Technologies 1200 chromatographic system, equipped with an Agilent photodiode array detector (DAD) 1200 with RFID tracking technology for flow cells, and a UV lamp, an automatic injector, and ChemStation software. The column was calibrated at $30^{\circ} \mathrm{C}$. The separation was performed on an Agilent-Eclipse XDB C-18 $4.6 \times$ $150 \mathrm{~mm}$ column. The HPLC method used was according to Radovanović et al. (2010) with some modification (elution gradient and flow rate). The HPLC grade solvents used were formic acid/water $(5: 95 \mathrm{v} / \mathrm{v})$ as solvent $\mathrm{A}$, and acetonitrile/ formic acid/water $(80: 5: 15 \mathrm{v} / \mathrm{v})$ as solvent $\mathrm{B}$. The elution gradient was linear as follows: from 0 to $10 \mathrm{~min}, 0.0 \%$ $\mathrm{B}$, from 10 to $28 \mathrm{~min}, 10.0 \% \mathrm{~B}$, from 28 to $35 \mathrm{~min}, 25 \%$ $\mathrm{B}$, from 35 to $40 \mathrm{~min}, 50 \% \mathrm{~B}$, from 40 to $45 \mathrm{~min}, 80 \%$ $\mathrm{B}$, and for last $10 \mathrm{~min}$ again $0 \% \mathrm{~B}$. The injection volume was $5 \mu \mathrm{L}$ and the flow rate was $0.9 \mathrm{~mL} / \mathrm{min}$. The detection wavelengths were 280, 320, 360 and $520 \mathrm{~nm}$ for UV, and $275 / 322 \mathrm{~nm}\left(\lambda_{\mathrm{Ex}} / \lambda_{\mathrm{Em}}\right)$ for fluorescence detection. The different polyphenolic compounds were identified by comparing their retention times and spectral characteristics with data of original reference standard compounds, and with data given in the literature (Revilla \& Ryan, 2000; Radovanović \& Radovanović, 2010). Quantification was accomplished using external calibration with pure standard solutions of gallic acid, caffeic acid, t-coutaric acid, p-coumaric acid, malvidin-3-Oglucoside, cyanidin-3-glucoside, $(+)$-catechin, procyanidin B2, (-)-epicatechin, (-)-epicatechin gallate, quercetin, rutin, quercetin-glucoside, luteolin-glucoside, myricetinglucoside and kaempferol-glucoside. The calibration curves (five data points, $\mathrm{n}=2$ ) were linear, with $\mathrm{R}^{2}=0.99$. Results were expressed as $\mathrm{mg} / \mathrm{g}$ sample (seed and skin) DM. The concentration of delphinidin-3-glucoside was expressed as cyanidin-3-glucoside equivalent, and concentrations of petunidin-3-glucoside, peonidin-3-glucoside were expressed as malvidin-3-glucoside equivalents.

\section{Antioxidant activity}

The free radical scavenging activity of the grape samples was analysed using a 2,2,-diphenyl-1-picrylhydrazyl (DPPH) assay (Choi et al., 2002; Munoz-Espada et al., 2004). The antioxidant assay was based on the measurement of the loss of DPPH colour by the change of absorbance at $517 \mathrm{~nm}$ caused by the reaction of DPPH with the tested sample. The reaction was monitored with a UV/VIS spectrophotometer. The diluted sample (extract was diluted with water, 1:10 v/v) and fresh $1 \times 10^{-4} \mathrm{M}$ DPPH methanolic solution were pipetted into cuvettes at room temperature. After $20 \mathrm{~min}$ incubation at room temperature, the absorbance was read against a blank (the absorbance of diluted sample extract) at $517 \mathrm{~nm}$. The radical scavenging activity of DPPH (\%) of each extract sample was calculated from the decrease of absorbance according to the following equation (Radovanović \& Radovanović, 2010):

Radical scavenging activity $(\mathrm{RSA}, \%)=\left(1-A_{\text {sample }}-A_{\text {blank }} /\right.$ $\left.A_{\text {control }}\right) \times 100$ where $A_{\text {control }}$ is the absorbance of the control reaction $\left(1 \times 10^{-4} \mathrm{M}\right.$ DPPH methanolic solution), $A_{\text {blank }}$ is the absorbance of the diluted sample extract, and $A_{\text {sample }}$ is the absorbance of the diluted sample extract with DPPH methanolic solution.

\section{Statistical analysis}

All the experiments were performed in triplicate. Values are presented as means \pm standard deviation. Significant differences were determined by analysis of variance (ANOVA), followed by the Tukey test. Data were analysed using the Origin software package, version 7.0.

\section{RESULTS}

Changes in berry weight (g per 100 berries), ${ }^{\circ} \mathrm{Brix}, \mathrm{pH}$, potential alcohol (vol \%) and titratable acidity $(\mathrm{mg} / \mathrm{L})$ during grape ripening are shown in Table 2. The sugar content of the five samples of different ripening stages ranged between 113.9 and $237.9 \mathrm{~g} / \mathrm{L}$, corresponding to a potential alcohol range of between 6.325 and 13.468 vol \%, respectively.

Total phenols in the grape seeds and skin were expressed as $\mathrm{mg}$ gallic acid equivalent (GAE) per $\mathrm{g}$ of dry matter (mg GAE/g DM), and in the pulp as mg GAE per $g$ of fresh pulp. The results show that the highest content of phenolics was in seed extracts and the lowest was in pulp extracts. The total phenol content (Fig. 1) ranged from $251.46 \pm 5.18$ to $315.45 \pm 7.17 \mathrm{mg} \mathrm{GAE} / \mathrm{g}$ of dry seeds, from $74.04 \pm 5.25$ to $112.83 \pm 4.27 \mathrm{mg} \mathrm{GAE} / \mathrm{g}$ of dry skin, and from $21.21 \pm 2.11$ to $58.53 \pm 3.77 \mathrm{mg} \mathrm{GAE} / \mathrm{g}$ of fresh pulp.

All the studied extracts showed high radical scavenging

TABLE 2

Effect of ripening on physiological parameters of grapes.

\begin{tabular}{clcllclc}
\hline $\begin{array}{l}\text { Days after } \\
\text { véraison }\end{array}$ & $\begin{array}{l}{ }^{\text {} B e r r y ~} \\
\text { weight }(\mathrm{g})\end{array}$ & $\mathrm{pH}$ & $\begin{array}{l}\text { Total soluble } \\
\text { solids } \\
\left({ }^{\circ} \text { Brix }\right)\end{array}$ & $\begin{array}{l}\text { Sugar } \\
\text { content } \\
(\mathrm{g} / \mathrm{L})\end{array}$ & $\begin{array}{l}\text { Potential } \\
\text { alcohol } \\
(\text { vol } \%)\end{array}$ & $\begin{array}{l}\text { Titratable } \\
\text { acidity } \\
(\mathrm{g} / \mathrm{L})\end{array}$ & $\begin{array}{l}\text { Maturity } \\
\text { index }\end{array}$ \\
\hline 0 & 215 & 3.03 & 11.5 & 113.9 & 6.325 & 32.44 & 0.354 \\
10 & 217 & 3.13 & 12 & 116.7 & 6.808 & 31.82 & 0.377 \\
20 & 226 & 3.31 & 16 & 152.4 & 9.028 & 15.21 & 1.052 \\
30 & 238 & 3.48 & 20 & 198.5 & 11.242 & 9.76 & 1.315 \\
40 & 201 & 3.68 & 23 & 232.7 & 13.191 & 5.10 & 4.509 \\
50 & 178 & 3.70 & 24 & 237.9 & 13.468 & 4.95 & 4.848 \\
\hline
\end{tabular}

${ }^{\text {a }}$ weight of 100 berries 
activity (Fig. 2). The highest radical scavenging activity was in seed extracts (from 77.73 to $82.22 \%$ ), follow by skin extracts (from 49.04 to $68.12 \%$ ) and pulp extracts (from 21.96 to $36.24 \%$ ).

Polyphenol composition at different harvest dates was determined by HPLC-DAD analysis and the results are shown graphically for the main polyphenols present in the seeds - flavan-3-ols: [(+)-catechin, (-)-epicatechin and procyanidin B2] in Fig. 3, and in the skin - quercetin and malvidin-3-glucoside in Fig. 4.
Total anthocyanins in skin extracts are shown in Fig. 4. They ranged from $33.46 \pm 1.52$ to $48.51 \pm 1.21 \mathrm{mg}$ malvidin-3- $O$ glucoside equivalent $(\mathrm{ME}) / \mathrm{g}$ of dry skin. The composition of individual polyphenol compounds estimated by HPLC found in Vranac grape seed and skin at optimal harvest is shown in Table 3.

\section{DISCUSSION}

The results show that, after véraison, there are physiological changes in the berries - a constant increase in the

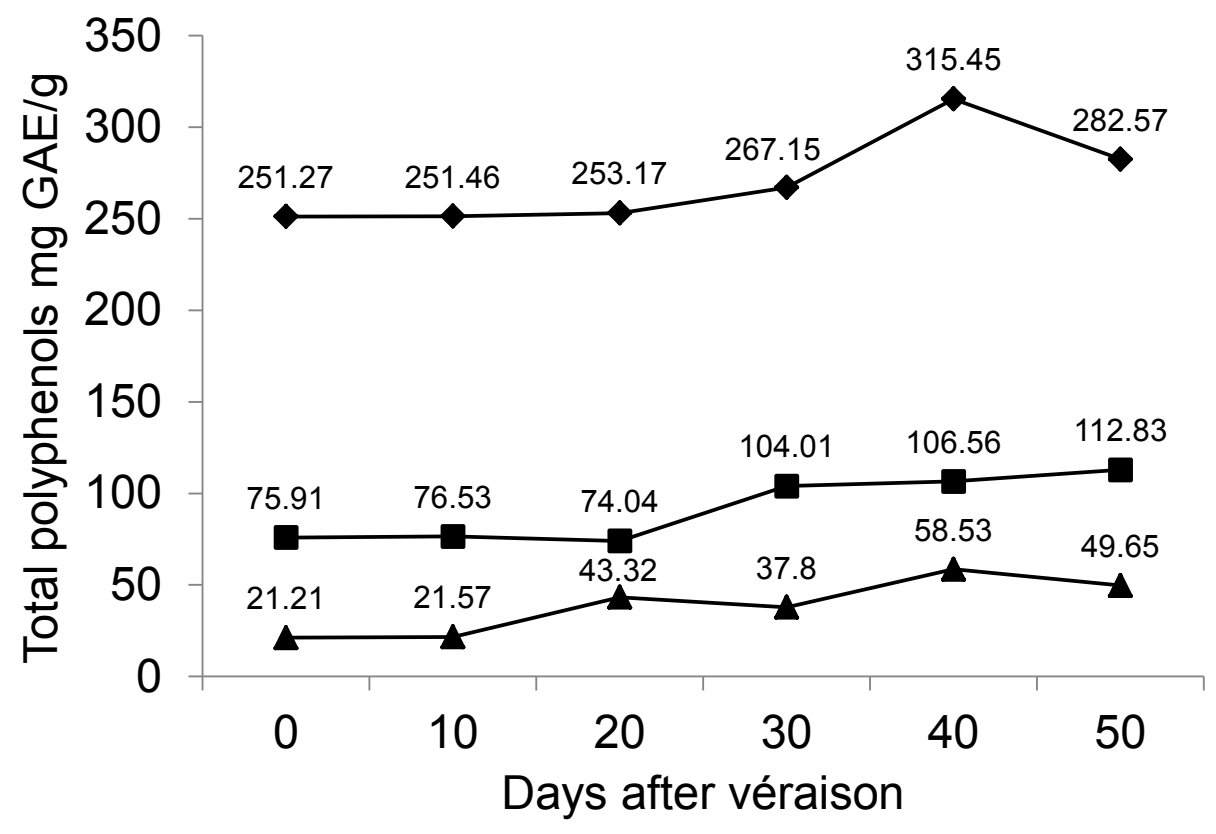

FIGURE 1

Polyphenol content during grape ripening in seeds ( $\bullet$ ), skin $(\boldsymbol{\bullet})$ and pulp $(\boldsymbol{\Delta})$. Results are mean \pm standard deviation $(\mathrm{n}=3$ ).

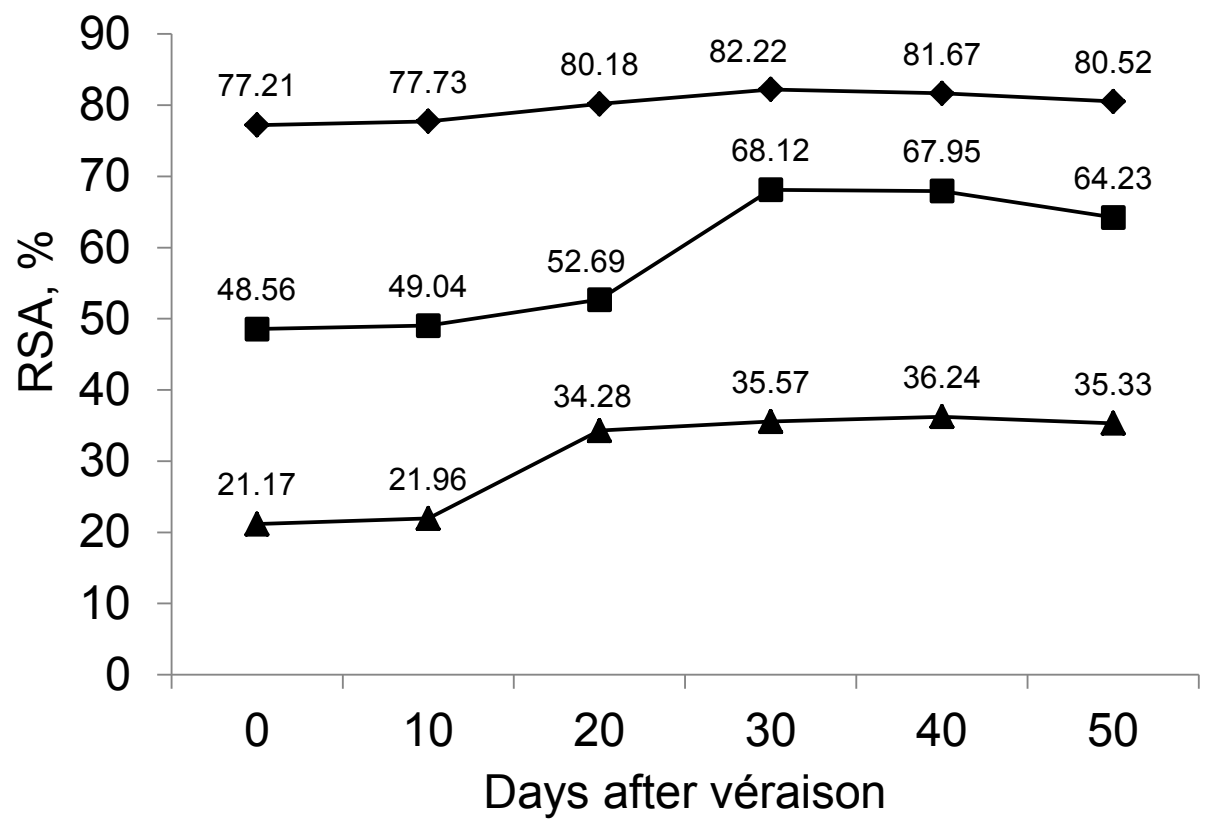

FIGURE 2

Radical scavenging activity (RSA) during grape ripening in seeds ( $\bullet)$, skin $(\boldsymbol{\square})$ and pulp ( $\mathbf{\Delta})$. Results are mean \pm standard deviation $(n=3)$. 
concentration of sugar, solid substances and $\mathrm{pH}$ in the berries, with a reduction in acidity. The weight of the berries at first indicates growth and reaches a maximum value at a sugar concentration of $198.5 \mathrm{~g} / \mathrm{L}$, and then slowly decreases (Table 2). Some authors explain the decrease in berry weight during berry ripening in terms of water deficit (Downey et al., 2003; Krasnow et al., 2009).

Beyond sugar accumulation, the major determinants of grape quality are the secondary metabolites - polyphenols. The concentrations of total phenols increased in the grape seed, skin and pulp during grape ripening, and then decreased slightly from the 40th day after véraison (Fig. 1). An increase in total phenol content during grape ripening has also been reported by Delgado (2004), O-Marques et al. (2005) and Canals et al. (2005), although decreases have also been reported (Obreque-Slier et al., 2010).

The concentration of flavan-3-ols also changed during grape ripening, especially that of (-)-epicatechin and procyanidin B2 (Fig. 3). From véraison to harvest, on the 30th day after véraison, the concentration of (-)-epicatechin and

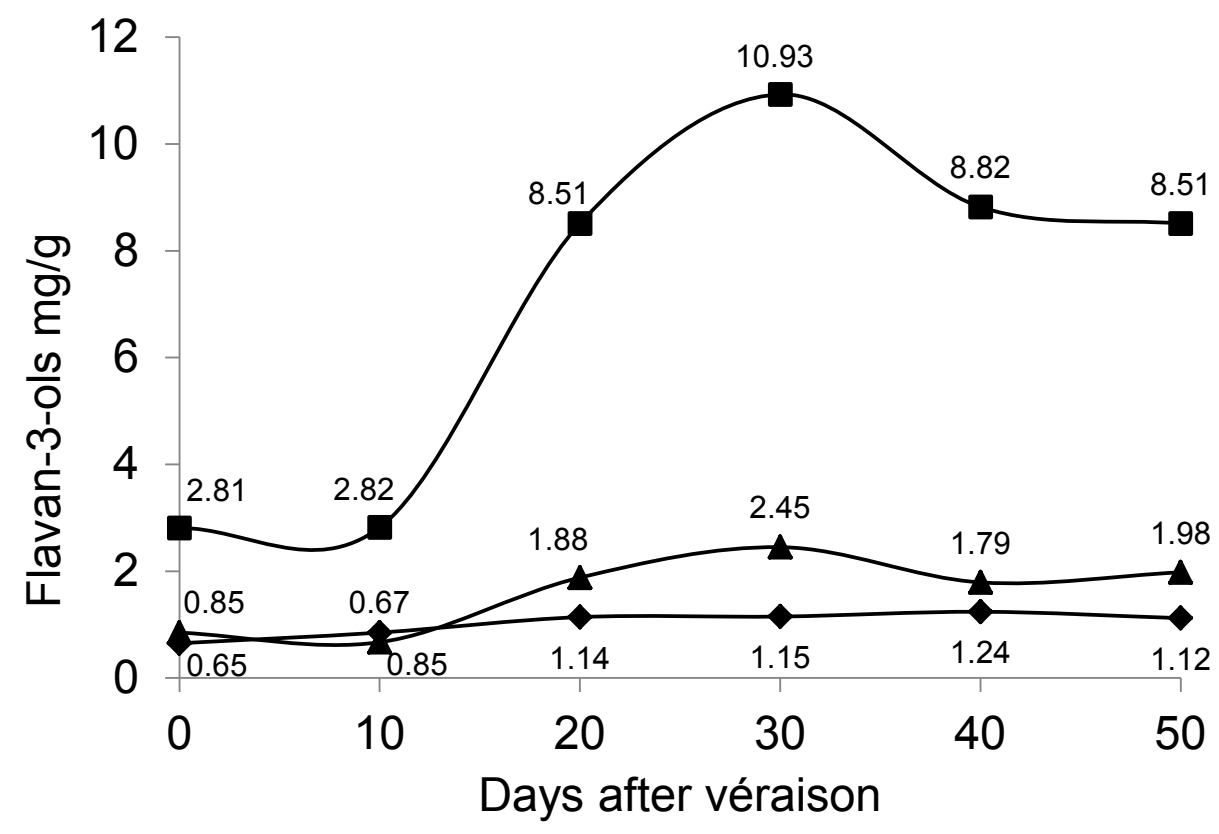

FIGURE 3

Content of flavan-3-ols: $(+)$-catechin ( $),(-)$-epicatechin $(\mathbf{\bullet})$, and procyanidin B2 $(\mathbf{\Delta})$ during grape ripening in seeds. Results are mean \pm standard deviation $(\mathrm{n}=3)$.

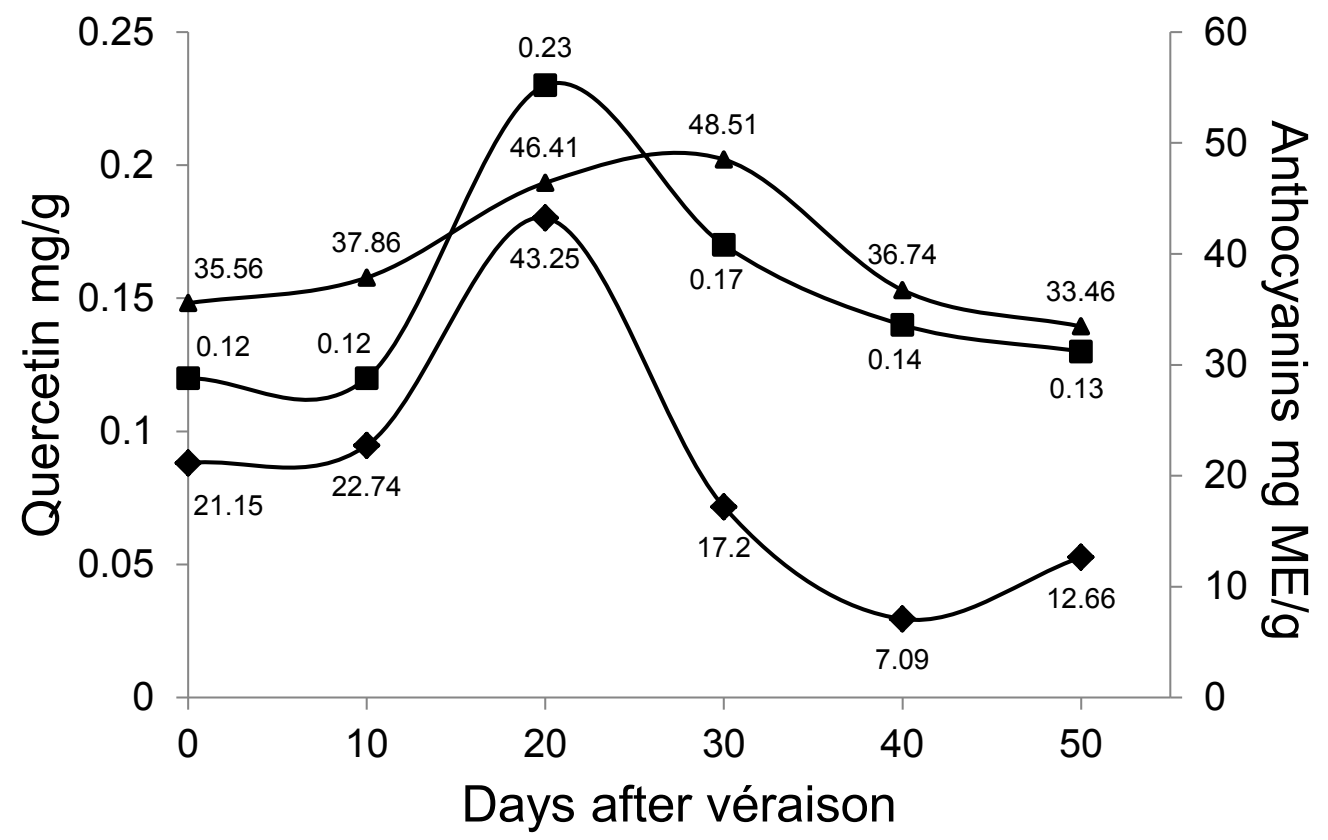

FIGURE 4

Quercetin ( $(\boldsymbol{\bullet})$, malvidin-3-glucoside $(\diamond)$ and total anthocyanin content $(\boldsymbol{\Delta})$ during grape ripening in skin. Results are mean \pm standard deviation $(\mathrm{n}=3)$. 
TABLE 3

Individual phenolic content (mg/g DM) in grape seeds and skins at optimal harvest time (30th day after véraison).

\begin{tabular}{|c|c|c|}
\hline Phenolic compound & Seeds & Skins \\
\hline Gallic acid & $0.850 \pm 0.012 \mathrm{c}$ & $0.410 \pm 0.012 \mathrm{c}$ \\
\hline t-Coutaric acid & $0.006 \pm 0.001 \mathrm{e}$ & $0.011 \pm 0.002 \mathrm{e}$ \\
\hline Caffeic acid & $0.004 \pm 0.001 \mathrm{e}$ & $0.085 \pm 0.008 \mathrm{e}$ \\
\hline p-Coumaric acid & $0.011 \pm 0.005 \mathrm{~d}$ & $0.009 \pm 0.001 \mathrm{e}$ \\
\hline Quercetin-glucoside & nd & $0.320 \pm 0.015 \mathrm{c}$ \\
\hline Rutin & nd & $0.440 \pm 0.013 c$ \\
\hline Luteolin-glucoside & nd & $0.240 \pm 0.010 \mathrm{c}$ \\
\hline Myricetin-glucoside & nd & $0.110 \pm 0.001 d$ \\
\hline Kaempferol-glucoside & nd & $0.090 \pm 0.001 \mathrm{~d}$ \\
\hline Quercetin & nd & $0.140 \pm 0.01 \mathrm{~d}$ \\
\hline$(+)$-catechin & $1.130 \pm 0.14 b$ & nd \\
\hline (-)-epicatechin gallate & $0.013 \pm 0.002 \mathrm{~d}$ & nd \\
\hline (-)-epicatechin & $7.450 \pm 0.32 \mathrm{a}$ & $0.018 \pm 0.003 \mathrm{e}$ \\
\hline Procyanidin B2 & $2.330 \pm 0.17 b$ & $0.027 \pm 0.004 \mathrm{e}$ \\
\hline Delphinidin-3-glucoside ${ }^{a}$ & nd & $3.280 \pm 0.220 \mathrm{~b}$ \\
\hline Cyanidin-3-glucoside & nd & $0.980 \pm 0.012 \mathrm{c}$ \\
\hline Petunidin-3-glucoside ${ }^{b}$ & nd & $3.600 \pm 0.440 b$ \\
\hline Peonidin-3-glucoside ${ }^{b}$ & nd & $2.410 \pm 0.370 \mathrm{~b}$ \\
\hline Malvidin-3-glucoside & nd & $7.090 \pm 0.590 \mathrm{a}$ \\
\hline Sum of glucoside derivatives ${ }^{c}$ & nd & $3.170 \pm 0.451 b$ \\
\hline
\end{tabular}

Values are the means \pm standard deviation $(n=3)$. nd, not detected

Means in the same column bearing different letters are significantly different $(p<0.05)$, as analysed by the Tukey test.

${ }^{a}$ The level of delphinidin-3-glucoside is expressed as cyanidin-3-glucoside equivalent.

${ }^{\mathrm{b}}$ The levels of petunidin-3-glucoside and peonidin-3-glucoside are expressed as malvidin-3-glucoside equivalents.

${ }^{\mathrm{c}}$ Sum of malvidin, delphinidin, cyanidin, petunidin and peonidin glucoside (acetyl and coumaryl) derivatives (mg ME/g DW).

procyanidin B2 increased from 2.81 to $10.93 \mathrm{mg} / \mathrm{g}$ and from 0.65 to $2.45 \mathrm{mg} / \mathrm{g}$, and then decreased to 8.51 and $1.98 \mathrm{mg} / \mathrm{g}$ respectively. The concentration of $(+)$-catechin remained relatively constant from véraison to all harvest dates after véraison, varying between 0.85 and $1.12 \mathrm{mg} / \mathrm{g}$. Others have reported similar flavan-3-ol accumulation in grape seeds during grape ripening (Kennedy et al., 2000a; Ristic \& Iland, 2005; Liu et al., 2010; Obreque-Slier et al., 2010). This is due to the fact that this class of polyphenols has already formed before véraison (De Frietas et al., 2000; Kennedy et al., 2000a, 2001; Downey et al., 2003). The reduction in concentrations of flavan-3-ol monomers and tannins in grape seeds may result from the oxidation of phenolic compounds, due to which they are fixed to the seed coat and therefore are less available for extraction (Cheynier et al., 1997; Kennedy et al., 2000b). A decrease in skin tannin concentration during berry development has previously been attributed to tannin being more difficult to extract, possibly due to interactions with cell wall material (Hanlin et al., 2010).

The amount of quercetin in grape skin (Fig. 4) increased until the 20th day after véraison, and then decreased slightly. Obreque-Slier et al. (2010) reported a similar decrease in the amount of flavonols for the Cabernet Sauvignon and Carmenere varieties. Some authors have reported an increase in flavonol content during the ripening of grapes (Mori et al., 2004; Munoz et al., 2007).

The total anthocyanins accumulated rapidly in the grape skins during grape ripening after véraison and reached a maximum value at a sugar concentration of $198.5 \mathrm{~g} / \mathrm{L}$, and then slowly decreased (Fig. 4). Our results support previous studies examining the influence of grape ripening on total anthocyanins (Kennedy et al., 2002; Mori et al., 2007). The anthocyanin concentration decreased slightly with further increasing sugar concentration in the berry pulp; this can be explained by environment effects. During this period of grape development, the berries were exposed to solar radiation, high temperatures and low irrigation. Berry temperature, additionally fuelled by berry skin exposure to sunlight, can slowly inhibit the biosynthesis of anthocyanins (Tarara et al., 2008). Other works have also described dramatic effects of the environment and culture conditions on anthocyanin accumulation (Ryan \& Revilla, 2003; De la Hera Orts et al., 2005; Downey et al., 2006; Human \& Bindon, 2008).

Free radical scavenging activity (RSA, \%) can be expressed as the amount of extract needed to quench a certain amount of DPPH free radicals (Choi et al., 2002; MunozEspada et al., 2004). The decrease in the absorbance at 517 $\mathrm{nm}$ is taken as a measure of the extent of radical scavenging. Radical scavenging activity (RSA, \%) decreased in the following order: seed extracts $>$ skin extracts $>$ pulp extracts, which is in agreement with reported data (Lacopini et al., 2008; Anastasiadi et al., 2010; Butkhup et al., 2010). The correlation between phenolics found in extracts from grape seeds, skins and pulp and their radical scavenging activity 
(RSA) was significant. The highest correlation was between RSA and anthocyanins $\left(\mathrm{r}^{2}=0.986, \mathrm{p}<0.05\right)$, followed by RSA and total phenols $\left(r^{2}=0.952, p<0.05\right)$. Strong correlations suggested that the phenolic composition of the Vranac variety contributed significantly to the antioxidant capacities of grape extracts.

According to the changes in antioxidant activity and phenolics of the investigated grape extracts (Figs 2 to 4) and sugar accumulation in the pulp (Table 2), harvesting at the 30th day after véraison can be optimal for receiving grapes rich in antioxidants. The antioxidant-rich extracts of seeds and skins at optimal harvest time (30th day after véraison) are characterised in Table 3. The results in Table 3 show a significant and different polyphenol composition in the grape seeds and skins of the Vranac variety. The seeds were rich in flavan-3-ols, while the skins had less flavan-3-ols but were rich in flavonols and anthocyanins. We detected the phenolic acids in the grape seeds and skins as being gallic acid, t-coutaric acid, caffeic acid and p-coumaric acid. Butkhup et al. (2010) reported the presence of gallic acid in seeds and skins ( 0.278 and $0.164 \mathrm{mg} / \mathrm{g} \mathrm{DW}$ respectively), caffeic acid ( 0.0048 and $0.0158 \mathrm{mg} / \mathrm{g}$ DW respectively), ellagic acid and ferulic acid, but an absence of t-coutaric acid and p-coumaric acid. Anastasiadi et al. (2010) found that gallic and caffeoyltartaric acids were the only detected phenolic acids in the grape seeds and skins from four native Greek Vitis vinifera cultivars.

The composition and concentration of individual flavonols in the grape skins at optimal harvest time (Table 3) showed that glucosides of quercetin, myricetin, kaempferol and luteolin were predominant, but some amount of quercetin aglycone was also present, which is in agreement with the data of the flavonol composition in Syrah, Cabernet Gernischt, Cabernet Sauvignon, Merlot, Gamay, Pinot Noir and Shiraz skins (Jin et al., 2009; Butkhup et al., 2010). The quercetin-3-glucoside was found to be the more abundant flavonol in the skins of the Vranac variety, thus coinciding with data reported by other authors for Cabernet Sauvignon (Obreque-Slier et al., 2010) and Syrah, Cabernet Gernischt, Cabernet Sauvignon, Merlot, Gamay and Pinot Noir, where the concentrations of quercetin-3-glucoside were between 0.0103 to $0.358 \mathrm{mg} / \mathrm{g}$ DW (Jin et al., 2009). The data in the literature are contradictory about the presence of flavonol aglycones in the skins. Some authors have reported the presence of aglycones (Lacopini et al., 2008), while others have reported its absence (Cheynier \& Rigaud, 1986). The presence of flavonol aglycones in skin extracts is a consequence of the progressive hydrolysis of glycosides. This can also be the result of skin extraction into acidic media (Downey et al., 2007). We also found a significant concentration of rutin in Vranac skins, which is in agreement with the literature (Lacopini et al., 2008; Butkhup et al., 2010).

The composition of individual flavan-3-ols of the Vranac variety (Table 3) shows that flavan-3-ols are mostly concentrated in the seeds. They were also present in the skins, although in a significantly lower concentration, which is in agreement with reported data (De Freitas et al., 2000; Revilla \& Ryan, 2000; Sun et al., 2001; Downey et al., 2003; Lacopini et al., 2008; Obreque-Slier et al., 2010; Liu et al., 2010). Three flavan-3-ol monomers, (+)-catechin, (-)-epicatechin and (-)-epicatechin gallate, were detected in the grape seeds. In the seeds of the Vranac variety, (-)-epicatechin was the major flavan-3-ol monomer, while (-)-epicatechin gallate was present in trace amounts, which is consistent with data previously reported (Butkhup et al., 2010; Liu et al., 2010). Other authors have reported that (+)-catechin was the most abundant flavan-3-ol monomer in Cabernet Sauvignon and Marselan seeds (Kennedy et al., 2000a; Downey et al. 2003; Liu et al., 2010). Lacopini et al. (2008) reported concentrations of (+)-catechin in grape seeds of Merlot, Cabernet Sauvignon, Canaiolo, Colorino Vino, Foglia Tonda and Montepulciano of 1.38, 1.41, 1.40, 1.24, 0.67 and $2.05 \mathrm{mg} / \mathrm{g}$ DM respectively, and slightly lower concentrations of (-)-epicatechin at 1.31, 1.27, 2.05, 0.89, 0.47 and $1.64 \mathrm{mg} / \mathrm{g}$ DM respectively. The concentrations of oligomeric procyanidins in the grape seeds and skins were significantly higher in comparison with the monomers (Sun et al., 1998, 2001; O-Marques et al., 2005).

The flavan-3-ols that we detected in Vranac skins were (-)-epicatechin $(0.018 \pm 0.003 \mathrm{mg} / \mathrm{g} \mathrm{DM})$ and procyanidin B2 $(0.027 \pm 0.004 \mathrm{mg} / \mathrm{g} \mathrm{DM})$. Jin et al. (2009) reported the presence of $(+)$-catechin in skins of Syrah, Cabernet Sauvignon, Cabernet Gernischt, Merlot, Gamay, Yan 73 and Pinot Noir $(0.034,0.023,0.016,0.013,0.028,0.044$ and $0.008 \mathrm{mg} / \mathrm{g} \mathrm{DW}$ respectively), and its absence in two varieties, namely Zinfandel and Muscat Rose. These authors found (-)-epicatechin in the skins of Cabernet Gernischt, Merlot and Yan 73 (0.016, 0.037 and $0.079 \mathrm{mg} / \mathrm{g}$ DW respectively), but not in the skins of Cabernet Sauvignon, Syrah, Gamay, Pinot Noir, Zinfandel and Muscat Rose. Also, Pinot Noir, Zinfandel and Muscat Rose had an absence of procyanidin B2 and others procyanidins, while the rest of the varieties showed a presence of procyanidin $\mathrm{B} 2$ in concentrations ranging from $0.007 \mathrm{mg} / \mathrm{g}$ in Cabernet Gernischt to $0.037 \mathrm{mg} / \mathrm{g}$ DW in skins of the Merlot variety.

The composition of individual anthocyanins in Vranac skin at optimal harvest time showed that the main anthocyanins were monoglucosides of five anthocyanidins: delphinidin, cyanidin, petunidin, peonidin and malvidin. Malvidin-3-glucoside was found to be the most abundant in the skins of the Vranac variety $(7.09 \pm 0.59 \mathrm{mg} / \mathrm{g} \mathrm{DM})$. The order of abundance of other anthocyanin glucosides was as follows: petunidin $>$ delphinidin $>$ peonidin $>$ cyanidin. We also detected, in lower concentrations, acetyl and coumaryl monoglucoside derivatives of these five anthocyanins. Bindon et al. (2011) reported that malvidin-3-glucoside was the anthocyanin with the highest concentration in the skins of Merlot (between 208.57 and $411.97 \mathrm{mg} / \mathrm{kg}$ berry FW), followed by other glucosides: delphinidin, petunidin, peonidin and cyanidin (47.1 to $175.02,40.7$ to $120.00,33.4$ to 87.47 and 8.2 to $43.45 \mathrm{mg} / \mathrm{kg}$ berry $\mathrm{FW}$ respectively), and derivatives of these glucosides in significantly lower concentrations. Jin et al. (2009) also detected malvidinglucoside as the most abundant in the skins of nine red grape varieties, with concentrations between 3.058 and $7.459 \mathrm{mg} / \mathrm{g}$ DW, followed by other glucosides: delphinidin, petunidin, peonidin and cyanidin ( 0.048 to $6.97,0.077$ to $4.91,0.307$ to 3.342 and 0.041 to $3.118 \mathrm{mg} / \mathrm{g}$ DW, respectively). 


\section{CONCLUSIONS}

In addition to the standard physiological properties of grapes ( ${ }^{\circ}$ Brix, acidity, maturity index), the grape quality is largely influenced by the amount of polyphenols and their composition. High accumulation of sugar in the grape pulp during grape ripening correlated well with the accumulation of phenolics in the grape skins and seeds. We can conclude that the Vranac red grape cultivar possesses very good quality due to both the physiological properties of the grape and the significant portion of polyphenol compounds in the grape seeds, skins and pulp.

This study demonstrates that the Vranac variety represents an important source of dietary antioxidants. Strong correlations between radical scavenging activity and polyphenols suggest that the phenolic composition of the Vranac variety contributes significantly to the antioxidant capacity of the grape extracts.

Grapes are health-promoting foods and it is important to characterise different ripeness stages and to determine differences between seeds, skin and pulp extracts that represent natural sources of phytochemicals and may also be used in the formulation of functional foods. Optimal harvest time can be defined as a compromise between sugar/ acid balance in the pulp and seeds, and skin polyphenol concentration and composition. If we want to obtain grapes as health-promoting foods we can choose to harvest them when the grapes are rich in phenolics (in our study at the 30 th day after véraison).

\section{LITERATURE CITED}

Adams, D.O., 2006. Phenolics and ripening in grape berries. Am. J. Enol. Vitic. 3, 249-256.

Anastasiadi, M., Pratsinis, H., Kletsas, D., Skaltsounis, A.L. \& Haroutounian, S.A., 2010. Bioactive non-coloured polyphenols content of grapes, wines and vinification by-products: Evaluation of the antioxidant activities of their extracts. Food Res. Int. 43, 805-813.

Banini, A.E., Boyd, L.C., Allen, J.C., Allen, H.G. \& Sauls, D.L., 2006. Muscadine grape products intake, diet and blood constituents of nondiabetic and type 2 diabetic subjects. Nutrition 22, 1137-1145.

Bindon, K., Myburgh, P., Oberholster, A., Roux, K. \& Toit, C.D., 2011. Response of grape and wine phenolic composition in Vitis vinifera L. cv. Merlot to variation in grapevine water status. S. Afr. J. Enol. Vitic. 32, 7188 .

Butkhup, L., Chowtivannakul, S., Gaensakoo, R., Prathepha, P. \& Samappito, S., 2010. Study of the phenolic composition of Shiraz red grape cultivar (Vitis vinifera L.) cultivated in North-eastern Thailand and its antioxidant and antimicrobial activity. S. Afr. J. Enol. Vitic. 31, 89-98.

Canals, R., Llaudy, M.C., Valls, J., Canals, J.M. \& Zamora, F., 2005. Influence of ethanol concentration on the extraction of color and phenolic compounds from the skin and seeds of Tempranillo grapes at different stages of ripening. J. Agric. Food Chem. 53, 4019-4025.

Cheynier, V. \& Rigaud, J., 1986. HPLC separation and characterization of flavonols in the skins of Vitis vinifera var. Cinsault. Am. J. Enol. Vitic. 37, $248-252$.

Cheynier, V., Prieur, C., Guyot, S., Rigand, J. \& Moutounet, M., 1997. The structures of tannin in grape and wines and their interactions with proteins. In: Watkins, T.R. (ed). Wine nutritional and therapeutic benefits. ACS Symposium Series 661, American Chemical Society, Washington DC. pp. $81-93$.
Choi, C.W., Kim, S.C., Hwang, S.S., Choi, B.K., Ahn, H.J., Lee, M.Y., Park, S.H. \& Kim, K., 2002. Antioxidant activity and free radical scavenging capacity between Korean medicinal plants and flavonoids by assay-guided comparison. Plant Sci. 163, 1161-1168.

De Freitas, V.A.P., Glories, Y. \& Monique, A., 2000. Developmental changes of procyanidins in grapes of red Vitis vinifera varieties and their composition in respective wines. Am. J. Enol. Vitic. 51, 397-403.

De la Hera Orts, M.L., Martínez-Cutillas, A., López Roca, J.M., PérezPrieto, L.J. \& Gómez-Plaza, E., 2005. Effect d'une irrigation déficitaire sur la teneur en anthocyanes des raisins et des vins issus du cépage Monastrell. J. Int. Sci. Vigne Vin. 39, 47-55.

Delgado, R., 2004. Changes in phenolic composition of grape berries during ripening in relation to vineyard nitrogen and potassium fertilisation rates. J. Sci. Food Agric. 84, 623-630.

Del Pozo-Insfran, D., Del Follo-Martinaz, A., Talcott, S.T. \& Brenes, C.H., 2007. Stability of copigmented anthocyanins and ascorbic acid in muscadine grape juice processed by high hydrostatic pressure. J Food Sci. $72, \mathrm{~S} 247-\mathrm{S} 253$.

Downey, M.O., Dokoozlian, N.K. \& Krstic, M.P., 2006. Cultural practice and environmental impacts on the flavonoid composition of grapes and wine: A review of recent research. Am. J. Enol. Vitic. 3, 257-268.

Downey, M.O., Harvey, J.S. \& Robinson, S.P., 2003. Analysis of tannins in seeds and skins of Shiraz grapes throughout berry development. Aust. J. Grape Wine Res. 9, 15-27.

Downey, M.O., Mazza, M. \& Krstic, M.P., 2007. Development of a stable extract for anthocyanins and flavonols from grape skin. Am. J. Enol. Vitic. 58(3), 358-364.

Geenspan, P., Bauer, J.D., Pollock, S.H., Gangemi, J.D., Mayer, E.P., Ghaffar, A., Hargrove, J.L. \& Hartle, D.K., 2005. Antiinflammatory properties of the muscadine grape (Vitis rotundifolia). J. Agric. Food Chem. $53,8481-8484$.

Hanlin, R.L., Hrmova, M.H., Harbertson, J.F. \& Downey, M.O., 2010. Review: Condensed tannin and grape cell wall interactions and their impact on tannin extractability into wine. Aust. J. Grape Wine Res. 16, 173-188.

Human, M.A. \& Bindon, K.A., 2008. Interactive effect of ethephon and shading on the anthocyanin composition of Vitis vinifera L. cv. Crimson Seedless. S. Afr. J. Enol. Vitic. 29, 50-58.

Jin, Z.M., He, J.J., Bi, H.Q., Cui, X.Y. \& Duan, C.Q., 2009. Phenolic compound profiles in berry skin from nine red wine grape cultivars in northwest China. Molecules 14, 4922-4935.

Kennedy, J.A., Hayasaka, Y., Vidal, S., Waters, E.J. \& Jones, G.P., 2001. Composition of grape skin proanthocyanidins at different stages of berry development. J. Agric. Food Chem. 49, 5348-5355.

Kennedy, J.A., Matthews, M.A. \& Waterhouse, A.L., 2000a. Changes in grape seed polyphenols during ripening. Phytochem. 55, 77-85.

Kennedy, J.A., Matthews, M.A. \& Waterhouse, A.L., 2002. Effect of maturity and vine water status on grape skin and wine flavonoids. Am. J. Enol. Vitic. 53, 268-274.

Kennedy, J.A., Saucier, C. \& Glories, Y., 2006. Grape and wine phenolics: History and perspective. Am. J. Enol. Vitic. 3, 239-248.

Kennedy, J.A., Troup, G.J., Pilbrow, J.R., Hutton, D.R., Hewitt, D., Hunter, C.R., Ristic, R., Iland, P.G. \& Jones, G.P., 2000b. Development of seed polyphenolics in berries from Vitis vinifera L. cv. Shiraz. Aust. J. Grape Wine Res. 6, 244-254.

Krasnow, M., Weis, N., Smith, R.J., Benz, M.J., Matthews, M. \& Shackel K., 2009. Inception, progression, and compositional consequences of a berry shrivel disorder. Am. J. Enol. Vitic. 60, 24-34. 
Lacopini, P., Baldi, M., Storchi, P. \& Sebastiani, L., 2008. Catechin, epicatechin, quercetin, rutin and resveratrol in grape: Content, in vitro antioxidant activity and interactions. J. Food Compos. Anal. 21, 589-598.

Lee, J.H., Johnson, J.V. \& Talcott, S.T., 2005. Identification of ellagic conjugates and other polyphenolics in muscadine grapes by HPLC-ESI-MS J. Agric. Food Chem. 53, 6003-6010.

Liu, Y.X., Pan, Q.H., Yan, G.L., He, J.J. \& Duan, C.Q., 2010. Changes of flavan-3-ols with different degrees of polymerization in seeds of 'Shiraz', 'Cabernet Sauvignon' and 'Marselan' grapes after veraison. Molecules 15, 7763-7774.

Mazza, G., Fukumoto, L., Delaquis, P., Girard, B. \& Ewert, B., 1999. Anthocyanins, phenolics, and color of Cabernet Franc, Merlot, and Pinot Noir wines from British Columbia J. Agric. Food Chem. 47, 4009-4017.

Mori, K., Goto-Yamamoto, N., Kitayama, M. \& Hashizume, K., 2007. Loss of anthocyanins in red-wine grape under high temperature. J. Exp. Bot. 58, 1935-1945.

Mori, K., Sugaya, S. \& Gemma, H., 2004. Regulatory mechanism of anthocyanin biosynthesis in Kyoho grape berries grown under different temperature conditions. Environ. Control in Biol. 42, 21-30.

Mori, K., Sugaya, S. \& Gemma, H., 2005. Decreased anthocyanin biosynthesis in grape berries grown under elevated night temperature conditions. Sci. Hortic. 105, 319-330.

Munoz, N.C., Alonso, S.G., Romero, E.G., \& Gutieärrez, I.H., 2007. Flavonol profiles of Vitis vinifera red grapes and their single-cultivar wines. J. Agric. Food Chem. 55, 992-1002.

Munoz-Espada, A., Wood, K., Bordelon, B. \& Watkins, B., 2004 Anthocyanin quantification and radical scavenging capacity of Concord, Norton and Marechal Foch grapes and wines. J. Agric. Food Chem. 52, 6779-6786

Obreque-Slier, E., Pena-Neira, A., Lopez-Solis, R., Zamora-Marin, F., Ricardo-da Silva, J.M. \& Laureano, O., 2010. Comparative study of the phenolic composition of seeds and skins from Carmenere and Cabernet Sauvignon grape varieties (Vitis vinifera L.) during ripening. J. Agric. Food Chem. 58, 3591-3599.

O-Marques, J., Reguinga, R., Laureano, O. \& Ricardo-da Silva, J.M., 2005. Changes in grape seed, skin and pulp condensed tannins during berry ripening: Effect of fruit pruning. Ciencia Tec. Vitiv. 20, 35-52.
Radovanović, B. \& Radovanović, A., 2010. Free radical scavenging activity and anthocyanin profile of Cabernet Sauvignon wines from the Balkan Region. Molecules 15, 4213-4226.

Radovanović, B.C., Radovanović, A.N. \& Souquet, J.M., 2010. Phenolic profile and free radical-scavenging activity of Cabernet Sauvignon wines of different geographical origins from the Balkan region. J. Sci. Food Agric. $90,2455-2461$

Revilla, E. \& Ryan, J.M., 2000. Analysis of several phenolic compounds with potential antioxidant properties in grape extracts and wines by highperformance liquid chromatography-photodiode array detection without sample preparation. J. Chromatogr. A 881, 461-469.

Rigo, A., Vianello, F., Clementi, G., Rossetto, M., Scarpa, M., Vrhovsek, U. \& Mattivi, F., 2000. Contribution of the proanthocyanidins to the peroxy radical scavenging capacity of some Italian red wines. J. Agric. Food Chem. 48, 1996-2002.

Ristic, R. \& Iland, P.G., 2005. Relationships between seed and berry development of Vitis vinifera L. cv Shiraz: Developmental changes in seed morphology and phenolic composition. Aust. J. Grape Wine Res. 11, 43-58.

Rodrígez, M.R., Romero Peces, R., Chacón Vozmediano, J.L., Martínez, G.J. \& Romero García, E., 2006. Phenolic compounds in skins and seeds of ten grape Vitis vinifera varieties grown in a warm climate. J. Food Comp. Anal. 19, 687-693.

Ryan, J.M. \& Revilla, E., 2003. Anthocyanin composition of Cabernet Sauvignon and Tempranillo grapes at different stages of ripening. J. Agric. Food Chem. 51, 3372-3378.

Sun, B.S., Ricardo-da Silva, J.M. \& Spranger, M.J., 1998. Separation of grape and wine proanthocyanidins according to their degree of polymerization. J. Agric. Food Chem. 46, 1390-1396.

Sun, B.S., Ricardo-da Silva, J.M. \& Spranger, M.J., 2001. Quantification of catechin and proanthocyanidins in several Portuguese grapevine varieties and red wines. Ciencia Tec. Vitiv. 16, 23-24.

Tarara, J.M., Lee, J., Spayd, S.E. \& Scagel, C.F., 2008. Berry temperature and solar radiation alter acylation, proportion, and concentration of anthocyanin in Merlot grapes. Am. J. Enol. Vitic. 59, 3.

Tsanova-Savova, S., Ribarova, F. \& Gerova, M., 2005. (+)-Catechin and (-)-epicatechin in Bulgarian fruits. J. Food Comp. Anal. 18, 691-698.

Yinrong, L. \& Yeap Foo, L., 1999. The polyphenol constituents of grape pomace. Food Chem. 65, 1-8. 